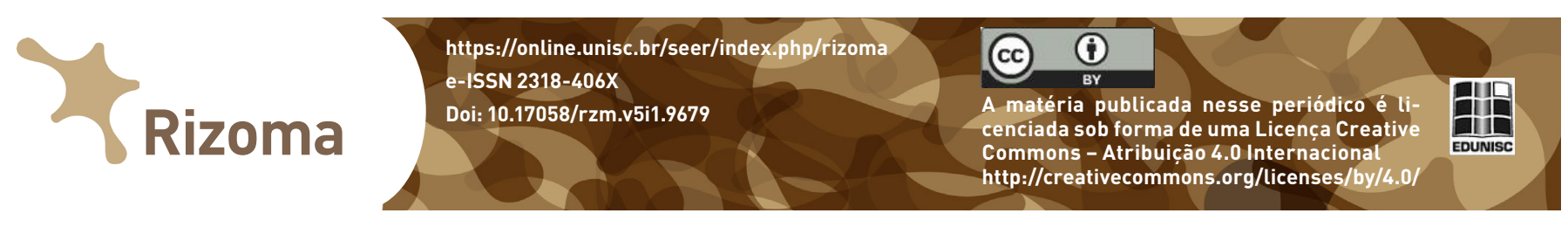

Resenha

\title{
Midiatização:
}

\section{um novo modo de ser e viver em sociedade}

\section{Demétrio de Azeredo Soster ${ }^{1}$}

GOMES, P. G.; FAXINA, E. Midiatização: um novo modo de ser em sociedade. São Paulo: Paulinas 2016.

Pensar a sociedade se realizando em uma perspectiva midiatizada, seja por meio da interposição cada vez maior de tecnologias entre os homens e suas ações, ou pela emergência de novos processos interacionais de referência de matizes midiatizados, nos moldes pensados por Braga (2012) em artigo seminal, requer que se observe, igualmente, que ambos os movimentos, para serem compreendidos, devem ser pensados processualmente. Isso porque, e aqui no diálogo com Bertalanffy (2013), metaforicamente, a partícula, ou excerto, ainda que integre uma processualidade mais ampla, não é suficiente para explicar toda a complexidade do sistema em que se insere, ainda que uma coisa não possa ser pensada sem a outra.

A perspectiva, uma vez adotada, nos permite compreender, de um lado, como sublinha Braga (2016), já na introdução deste livro, o acerto, e a importância, da abordagem metodológica proposta pelos autores na obra, antes processual que atomística. Ou seja, voltada à compreensão - e eis a hipótese central - de que a midiatização se estrutura “(...) como um projeto global, de unidade, superando o modo como a comunicação vem sendo considerada no momento atual" (FAXINA; GOMES, 2016, p. 19).

Este projeto, por sua vez, e eis aqui uma visada que empresta um grau significativo de originalidade à reflexão proposta, é pensado, de um lado, pelo viés da filosofia, enquanto que, de outro, por matizes complexos e sistêmicos. No primeiro caso, e após uma breve contextualização cuja ênfase recai sobre a lenta e gradual passagem da sociedade das mídias para a sociedade em processo de midiatização, a opção é, inicialmente, pela fenomenologia de Husserl, Heidegger e Merleau-Ponty. Escolhas originais em um universo reflexivo de nuanças marcadamente sociológicas; sobretudo, precisas quando o assunto é compreender a "essência" desse novo modo de ser em sociedade:

\begin{abstract}
${ }^{1}$ Possui graduação em Jornalismo pela Universidade do Vale do Rio dos Sinos (Unisinos, 1990), mestrado em Comunicação e Informação pela Universidade Federal do Rio Grande do Sul (Ufrgs, 2003) e doutorado em Ciências da Comunicação pela Universidade do Vale do Rio dos Sinos (Unisinos), de São Leopoldo, Rio Grande do Sul. Já trabalhou como assessor de imprensa, repórter, repórter especial, subeditor, editor, editor multimídia, editor-executivo e gerente de redação. Atualmente é professor de jornalismo da Universidade de Santa Cruz do Sul (Unisc). Atua em docência de jornalismo, extensão, pesquisa e desenvolvimento de jornais e revistas-laboratório. Foi diretor administrativo da Associação Nacional dos Pesquisadores em Jornalismo (SBPJor), diretor Científico do Fórum Nacional dos Professores de Jornalismo (FNPJ), chefe de departamento e coordenador do Curso de Comunicação Social da Unisc. É pesquisador e professor do Programa de Pós-graduação em Letras da Unisc, membro pesquisador da Rede de Pesquisa Aplicada Jornalismo e

Tecnologias Digitais JORTEC, da SBPJor; do Grupo de Pesquisa Hipermídia e Linguagem, da Universidade Federal de Santa Catarina (UFSC), e do Grupo de Pesquisa Leitura, Literatura e Cognição, da Universidade de Santa Cruz do Sul (UNISC).
\end{abstract}




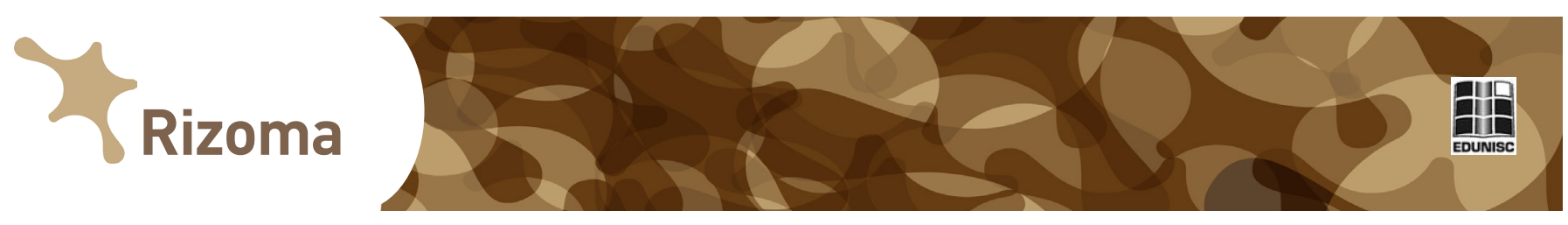

a mídia e o modo como ele justifica e tematiza essa mesma relação. Por isso, estrutura-se como um processo social mais complexo que traz no seu bojo os mecanismos da produção de sentido social. (FAXINA, GOMES, 2016, p. 50).

Eis o conceito-chave para a compreensão, e o acerto, da abordagem fenomenológica: compreender a produção de sentido na perspectiva proposta. Com isso, os autores se unem ao pequeno, porém expressivo, grupo de pesquisadores que vão pensar a comunicação, se não notadamente pela filosofia, como faz Ciro Marcondes Filho, por exemplo, pelo que ela, a comunicação, tem de transformadora, como o faz o Muniz Sodré. Ou seja, é, antes, compreender "o que se transforma" do que "como se transforma", sem deixar de considerar este na reflexão.

Compreender a essência, no entanto, não basta; é preciso, ainda, e antes de lhe emprestar matizes mais largos, complexos, rizomáticos, dizer de sua origem, o que é feito no capítulo seguinte - O uno, o múltiplo e a comunicação. Aqui, Platão, Plotino, Santo Agostinho, os filósofos da Idade Média até Nicolau de Cusa servem de ponto de partida para resgate do conceito de unidade, “(...) visto que este pode constituir uma chave para a interpretação desta nova ecologia comunicacional e para a compreensão do bios midiático que está se estruturando no presente" (FAXINA; GOMES, 2016, p. 71).

Ocorre que os filósofos antigos, não obstante sua percepção do conceito de unidade como base explicativa para o mundo, sempre que o buscaram fizeram-no pela perspectiva metafísica, transcendente. Caberá a Teilhard de Chardin (2016, p. 87), “(...) um filósofo cristão que apresenta uma metafísica original (...)", considerar a unidade também a partir das coisas do mundo, ou seja, "(...) a partir dos fenômenos de complexificação da matéria, compreensão das massas humanas, globalização etc.”. Tem-se, dessa maneira, o vínculo entre dois mundos - o antigo e o contemporâneo, pelo viés da unidade.

É no capítulo seguinte, no entanto, pelo viés das teorias dos sistemas e da complexidade, que este sentido de conjunto se atualiza, ganhando contornos de um lado, sistêmicos; de outro, complexos. Mais que perspectivas antagônicas - a complexidade de Maturana e Varela tensionadas pela abordagem sistêmica de Luhmann, por exemplo - tem-se, aqui, e também ao lado de Edgar Morin e Manuel Castells, a possibilidade, quem sabe, de se pensar a referida unidade em termos de uma sociedade que dialoga pelo viés da tecnologia, em rede. E que tem, como se observa no capítulo seguinte, a partir uma vez mais de Chardin, mas, também, de Marshall McLuhan, as tecnologias como "extensões da nervura humana".

Chega-se, por fim, à questão da midiatização propriamente dita, o que é feito no diálogo com Dominique Wolton, Jesús Martín-Barbero, e, finalmente, Muniz Sodré, este para se pensar o estágio atual da midiatização.

A concepção de midiatização a que chegamos e defendemos tem em vista perceber justamente as complexas relações da mídia na sociedade, observando que a totalidade desses dispositivos tecnológicos de produção, criação e difusão midiática nos leva a uma totalidade sistêmica que altera qualitativamente a esfera da esfera humana. (FAXINA; GOMES, 2016, p. 180-181). 

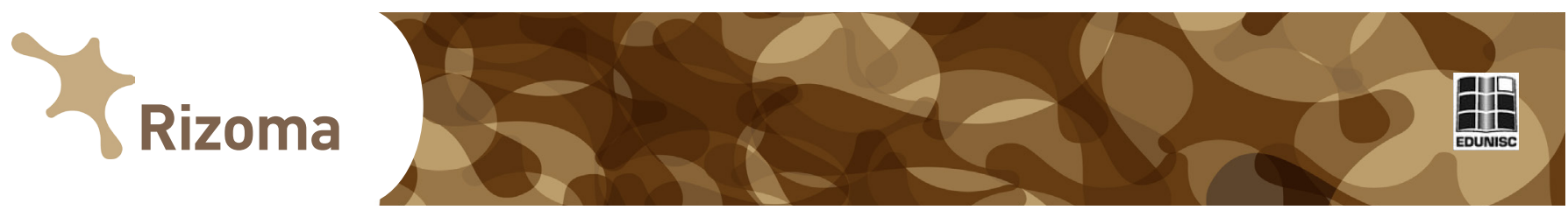

O que temos com isso? A configuração de uma ambiência - de onde o uno, a unidade; a noção de tecido rizomático - em que o ser se estabelece na relação com o meio, de forma que um não possa ser pensando sem o outro. Ou, como concluem os autores, "A sociedade é em midiatização. O ser humano é em midiatização. Isso, hoje, sublinha-se, configura um novo modo de ser e viver em sociedade" (FAXINA; GOMES, 2016, p. 188).

\section{Referências}

BERTALANFFY, Ludwig von. Teoria geral dos sistemas. Rio de Janeiro: Vozes, 2013.

BRAGA, José Luiz. Circuitos versus campos sociais. In: MATTOS, M. A., JANOTTI JUNIOR, J.; JACKS, N. (Orgs). Mediação \& midiatização [online]. Salvador: EDUFBA, 2012.

MATTOS, M. A., JANOTTI JUNIOR, J.; JACKS, N. (Orgs). Mediação \& midiatização [online]. Salvador: EDUFBA, 2012.

FAXINA, Elson; GOMES, Pedro Gilberto. Midiatização: um novo modo de ser e viver em sociedade. São Paulo: Paulinas, 2016. 